\title{
El cuerpo y el Otro en Merleau-Ponty y Lévinas
}

\author{
The Body and the Other in Merleau-Ponty and Lévinas
}

\author{
Leonardo Verano Gamboa*
}

Universidad del Norte, Barranquilla, Atlántico, Colombia

A Farides Lugo

\section{Resumen}

El presente trabajo se propone mostrar que en la filosofía de Merleau-Ponty y de Lévinas la vida del cuerpo (Leib) adquiere un rol decisivo en el reconocimiento de la alteridad del Otro. En la figura de la carne (chair) y del rostro (visage) Merleau-Ponty y Lévinas, respectivamente, encuentran la manera de hablar de una "dimensión profunda" del Otro y de nosotros mismos, irreductible a cualquier intento de objetivación. La "carne", como el tejido sensible que nos ata al mundo, es carne del cuerpo del otro, la "expresión" misma de su ser sensible, así como el "rostro" del otro, su exterioridad, es la "expresión" misma de su alteridad. Ambos conceptos -carne y rostro- refieren, no un ser trascendental desprovisto de cuerpo, sino una trascendencia absoluta, incomparable, que es facticidad y sensibilidad. Sin embargo, para los autores la alteridad radical del otro se pone en evidencia en la experiencia del lenguaje. Nos preguntamos, entonces, de qué modo la palabra del otro, y nuestra propia palabra, expresan la alteridad radical del otro y hasta qué punto esta alteridad puede ser entendida como una 
alteridad corporal. En tres apartados buscamos dar cuenta de este planteamiento: 1. El cuerpo y el otro, 2. La carne y el rostro y 3 . El otro y la palabra.

Palabras clave: Carne. Rostro. Otro. Mirada. Palabra.

\section{Abstract}

This current work intends to show that in the philosophy of Merleau-Ponty and Lévinas the life of the body (Leib) acquires a decisive role in the recognition of the alterity of the other. In the figure of the flesh (chair) and the face (visage) Merleau-Ponty and Lévinas, respectively, both find the way of speaking of a "deep dimension" of the Other and of ourselves, irreducible to any attempt at objectification. The "flesh", as the sensitive tissue that binds us to the world, is the flesh of the body of the other, the very "expression" of its sensitive being, as well as the "face" of the other, its exteriority, is the "expression" itself of its alterity. Both concepts -flesh and face-refer, not a transcendental being devoid of body, but an absolute, incomparable transcendence, which is facticity and sensitivity. However, for the authors the radical alterity of the other is evident in the experience of language. We ask, then, how the word of the other, and our own word, express the radical alterity of the other and to what extent this alterity can be understood as a corporal alterity. In three sections we look forward to presenting this approach: 1. The body and the other, 2. The flesh and the face 3. The other and the word.

Keywords: Flesh. Face. Other. Look. Word.

\section{Introducción}

Tanto Merleau-Ponty como Lévinas critican abiertamente los peligros de un totalitarismo de la razón, propio de un pensar que no otorga sentido y valor más que a lo que él mismo ha establecido como principio y verdad. Se trata de la crítica, en los dos autores, a una razón solipsista, sin espacio, sin historia. Para Merleau-Ponty es la idea la razón como razón abstracta, intelectual, característica de un espíritu sin cuerpo, sin espacio, la que termina por convertir al otro en un objeto de 
su pensamiento, en una simple proyección suya. Para Lévinas el mayor peligro de esta razón se encuentra en el planteamiento ontológico de una idea del ser como fundamento de todo lo que existe. No existe nada fuera de él, él lo engloba todo y es la razón de todo lo existente. Ambos autores critican a Husserl el hecho de tomar como absoluta y evidente la reflexión pura, aunque su propio pensamiento permanezca en deuda con aspectos centrales de la obra del filósofo alemán. Sus planteamientos coinciden ${ }^{1}$ en criticar la idea de una razón capaz de explicarlo todo, incluso aquellas regiones que se reconozcan poseedoras de un sentido irreflexivo, inconsciente. La propuesta filosófica de los autores comparte la idea de elaborar, aunque en direcciones de pensamiento distintas, una filosofía que esté en condición de reconocer la pluralidad, de no disolver a esta en la unidad cerrada de sus principios; en elaborar una filosofía, dirá Merleau-Ponty en su obra Lo visible y lo invisible, con "varias entradas", capaz de seguir la explosión, la diseminación de la vida sensible; en "abrirse camino [afirmará Lévinas en su primera obra El tiempo y el otro] hacia un pluralismo que no se fusiona en una unidad y que nos permitiría - si es que tal cosa puede intentarse - romper con Parmenides" (LÉVINAS, 1993, p. 80).

Merleau-Ponty elaborará una filosofía del cuerpo y de la carne capaz de reconocer lo que son el mundo, las cosas y los otros antes de toda reflexión, de toda tematización explícita; una filosofía en la que el mundo y la existencia se comprendan a partir de su propia facticidad (MERLEAU-PONTY, 1945, p. I; 1984, p. 7). Lévinas, por su parte, elaborará una filosofía de la alteridad, en la que sea posible el reconocimiento de la diferencia del otro, entendida esta como lo absolutamente otro del otro, en el sentido de lo incomparable, de lo irrepresentable, de lo irreductible; una filosofía de la alteridad en clave ética, basada en la idea de la responsabilidad para con el otro como respuesta ineludible

Debe aclararse que no proponemos en este texto un diálogo entre Merleau-Ponty y Lévinas que busque hacer coincidir sus principales presupuestos y desarrollos teóricos, en el sentido de ver en la filosofía de la alteridad de ambos autores, como lo plantea por ejemplo Jairo Gutiérrez (2010), una propuesta ética. Nuestro interés se limita a precisar los alcances que tienen las consideraciones sobre el cuerpo en su concepción de la alteridad, más que en buscar afinidades y diferencias en las vertientes fenomenológica - de herencia husserliana- u ontológica -de herencia heideggeriana- 0 en querer explorar en sus obras los alcances y límites de la fenomenología frente a la problemática del otro. Ver al respecto el trabajo de Ricardo Salas (2011).

Rev. Filos., Aurora, Curitiba, v. 30, n. 50, p. 379-396, maio/ago. 2018 
a las interpelaciones que se anuncian en su rostro; una filosofía que, en últimas, piense la alteridad del otro "más allá" de la esencia, "más allá" del ser, esto es, más allá de la inmanencia de la vida del yo ${ }^{2}$. El camino emprendido por Merleau-Ponty será el de un pensar del adentro, el de una intra-ontología que piense al ser desde dentro del ser, en la que no haya cabida para un pensar de sobrevuelo, para una mirada absoluta, sin perspectiva, característica de un pensar totalizante; Lévinas recorrerá el camino de una filosofía de la exterioridad, en el modo de una primacía del Otro que haga posible pensar la trascendencia de este como una trascendencia absoluta, imposible de ser derivada de la inmanencia de un sujeto trascendental. Sostenemos en este trabajo que tanto para MerleauPonty como para Lévinas la vida del cuerpo es decisiva para el reconocimiento de la alteridad del otro. Es en virtud del cuerpo del otro, para Merleau-Ponty, como es posible reconocer su ser completamente otro; es por nuestro cuerpo que, de acuerdo con Lévinas, estamos abiertos al otro, al sentido de su altura, de su ser absolutamente otro, inaprehensible.

\section{El cuerpo y el otro}

El cuerpo (Leib) posee, tanto en Merleau-Ponty como en Lévinas, un estatuto ontológico ${ }^{3}$ : es por nuestro cuerpo que nos encontramos vinculados esencialmente a las cosas, a los demás, al mundo ${ }^{4}$. El cuerpo, como el vínculo que nos ata al mundo y a los otros, no funge como fundamento

2 Se debe anotar también que las exigencias para llevar a cabo su proyecto filosófico serán similares en cada autor: necesidad de volver a pensar las nociones de sujeto, mundo, ser, esencia, historia y, con ellas, la idea de trascendencia.

3 La crítica contundente de Lévinas a la ontología no significa su negación, como bien observa Waldenfels (cf. 1987, p. 221-222). Para el filósofo alemán la obra de Lévinas propone, incluso en su primera fase -en el Tiempo y el otro- una nueva concepción del ser que no hace de este el fundamento último de todo sentido. La existencia de un fuera (Ausserhalb), de un más allá (Über-hinaus) del ser o "de otro modo que ser", es la afirmación de la idea de un ser "ahuecado", "agujereado" que admite la discontinuidad, el absurdo, el sinsentido, el horror (cf. WALDENFELS, 1987, p. 221). Ver también Waldenfels (2015), p. 259.

4 El vínculo corporal que nos ata al mundo pone en evidencia el nacimiento de un sujeto anterior a la reflexión, y con él, la existencia de hecho, fáctica, de los demás seres en el mundo, la imposibilidad de derivarlos del análisis reflexivo, a modo de simples elementos que integran un sistema total de explicación. Es en la existencia corporal, en la vida prereflexiva del cuerpo, donde el mundo y los demás seres mantienen una identidad inquebrantable, imposible de ser subsumida por principios universales.

Rev. Filos., Aurora, Curitiba, v. 30, n. 50, p. 379-396, maio/ago. 2018 
(Grund) último del sentido, sino como el lugar de su articulación. Ambos autores, aunque desde desarrollos claramente distintos, entiende por cuerpo el cuerpo vivo (Leib), esto es, no el cuerpo como producto o descubrimiento de la conciencia, sino justamente la vida del cuerpo, el cuerpo que en cada caso somos ${ }^{5}$ : esa materialidad sensible que satisface necesidades, que se desplaza, siente, sueña, padece. El cuerpo, dicho en otras palabras, "con" el que despertamos y "con" el que vamos a dormir.

Con el fin de enfatizar el sentido ontológico del cuerpo, MerleauPonty sostiene que la concepción heideggeriana del Da-sein como seren- el mundo (étre dont le monde; zur-Welt-Sein), debe ser entendida, en sentido estricto, como ser-del-mundo (étre au monde; zur-Welt-Sein). No sólo nacemos al mundo, esto es, no sólo nos hacemos visibles para los demás por nuestro cuerpo, sino que vivimos corporalmente en el mundo, en el sentido de que este es mundo de nuestra experiencia sensible, corporal. El mundo, en otras palabras, se encuentra encarnado en nuestra experiencia sensible. Merleau-Ponty entiende esta experiencia como un fenómeno fundamentalmente reversible. Ver, tocar, significa ser visto, ser tocado. Incluso hablar, como experiencia de la palabra encarnada en nuestro cuerpo, significa "ser hablado". La experiencia sensible, corporal, consiste en este vínculo de entrelazamiento mutuo entre quien ve y lo visto, entre quien toca y lo tocado, entre quien habla y lo hablado, vínculo que no está dado en los términos de una relación sujeto-objeto. Este poder reversible de lo sensible, como una vuelta a sí mismo desde lo otro, que convierte a lo visto en vidente, a lo tocado en tocante, a quien escucha en hablante, permite comprender que en la percepción sensible del otro - verlo, tocarlo, escucharlo- este no aparece en calidad de objeto, sino justamente como otro sujeto, como otro yo y, en este sentido, como radicalmente distinto

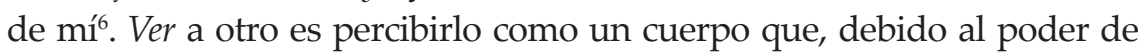
reversibilidad de lo sensible, además de ser visible, es vidente. Percibir al

5 Lévinas señala, en su obra temprana dedicada a Husserl Théorie de l'intuition dans la phénoménologie de Husserl (2001), que los análisis del filósofo alemán sobre la vida concreta, propios de la actitud natural, la toman en su riqueza y plenitud, pero como vida pensada y no como vida vivida (cf. LÉVINAS, 2001, p. 203; 2004, p. 175).

6 No se trata de una "proyección", en la que la experiencia de ver a otro signifique la constatación de estar viendo a otro "como yo" 0 a otro "igual que" yo, justamente porque en la experiencia sensible el otro es percibido como un ser corporal. 
otro como tal, como verdaderamente otro, es, en otras palabras, percibirlo como un cuerpo que tiene el poder de la visión?.

Lévinas, por su parte, planteará, de forma similar, un poder de inversión del cuerpo, capaz de romper con la idea de un sentido fundado exclusivamente en la razón y de hacer surgir, de este modo, una "lógica" del sentido en la vida material del sujeto que esté en condición de explicar la existencia de una alteridad radical del otro. El nacimiento del sujeto, de un sí mismo anterior a la reflexión, a la indagación explícita, es sólo posible en la existencia material, corporal. Nos ocupamos de nosotros mismos, nos hacemos responsables de nuestra existencia, porque somos cuerpo. Este, advierte Lévinas en El tiempo y el Otro, no expresa la caída, el encarcelamiento del alma, sino la posibilidad misma de la emergencia del sujeto (LÉVINAS, 1993, p. 94), pero no porque el cuerpo preexista a éste, a modo de su fundamento (Grund), sino porque "acompaña" siempre su nacimiento ${ }^{8}$. Lévinas advierte que, contra Heidegger, el "hay" es un "hay" factico, expresión de la estructura material de la existencia. Vivir consiste en superar nuestra condición ontológica material de seres encarnados en el mundo, en buscar, en términos del autor, nuestra salvación, en satisfacer nuestras necesidades materiales; labor que muestra a su vez la imposibilidad de la superación definitiva de nuestra facticidad $\mathrm{y}$, con ello, la profundidad de nuestro ser encarnado.

El egoísmo que caracteriza a esta vida pone en evidencia su ser trascendente con la idea del goce como salida de sí, como éx-tasis, contacto con el exterior, disfrute de los objetos. La idea del goce no se circunscribe, entonces, al disfrute de los alimentos, sino que indica el modo mismo en que vivimos en el mundo9. El hombre, dirá Lévinas al respecto en su obra Totalidad e Infinito, tiene el poder de aferrarse al mundo, de hacer estancia en él, en una tierra que le es exterior, "como un cuerpo que se sostiene y

7 Al respecto afirma Merleau-Ponty: "Cuando digo: veo que ve no hay, como cuando digo pienso que piensa, acoplamiento de dos proposiciones, una dentro de la otra, visión "principal" y visión "subordinada" se descentran la una a la otra" (MERLEAUPONTY, 1964a, p. 206-207).

8 Este planteamiento supone partir, como en Heidegger y Merleau-Ponty, de una existencia anónima, del hecho de que "hay"sentido, esto es, de que existen el mundo, los otros, antes del nacimiento de la conciencia reflexiva, de la toma de posición deliberada del sujeto racional. Para Merleau-Ponty y Lévinas la vida anónima del cuerpo no niega la existencia de un sujeto corporal.

9 El disfrute abarca todas las sensaciones y, en este sentido, nuestra vida afectiva. (cf. LÉVINAS, 2012, p. 207-208).

Rev. Filos., Aurora, Curitiba, v. 30, n. 50, p. 379-396, maio/ago. 2018 
puede" (LÉVINAS, 2012, p. 32). El disfrute muestra, de manera ejemplar, una intencionalidad, un movimiento trascedente distinto a la intencionalidad de la representación ${ }^{10}$ : consiste en atenerse a la exterioridad, en "plantarse o ponerse corporalmente en él" (LÉVINAS, 2012, p. 137).

Pero ¿de qué modo esta existencia corporal dedicada al cuidado de sí misma revela la alteridad del otro? Planteado en otros términos, ¿en qué medida el nacimiento de la conciencia como un sí mismo corporal muestra la existencia del Otro? Lévinas encuentra en su obra Totalidad e Infinito, según nuestra opinión, una formulación que evidencia, de forma más explícita, la importancia que adquiere el cuerpo en la problemática de la alteridad: “[...] el egoísmo humano sale de la pura naturaleza gracias al cuerpo humano, erguido hacia lo alto, abierto al sentido de la altura. El cuerpo no es la ilusión empírica de todo ello, sino su producción ontológica y el testimonio irrecusable en su favor. El yo puedo procede de esta altura" (LÉVINAS, 2012, p. 125). Existir como cuerpo es estar abierto al otro, al sentido de su altura, a su distancia inalcanzable, insuperable. Esto es posible porque el cuerpo no se esclaviza en la satisfacción de sus necesidades materiales, sino que, por el contrario, tal satisfacción lo libera de su dependencia y le da tiempo, en el sentido de poder ser él mismo (cf. LÉVINAS, 2012, p. 124-125). El tiempo describe la ruptura con la dependencia y, en este sentido, su vínculo estrecho con el cuerpo como el poder de ser sí mismo en tanto salida de $\mathrm{s}^{11}$. Es el movimiento trascendente que nos lanza al dominio del mundo el que se convierte "en interior a la exterioridad que constituye" (LÉVINAS, 2012, p. 140). Esta inversión de sentido es esencialmente corporal: el cuerpo es el lugar de la articulación recíproca entre la interioridad y la exterioridad: "El cuerpo indigente y desnudo, [afirma Lévinas], es este mismo cambio de sentido" (LÉVINAS, 2012, p. 140). Cuerpo "indigente y desnudo" porque no está protegido por el concepto y la representación, pero que, no obstante, es el lugar del

10 Para Lévinas la idea de la representación permanece en el dominio de la constitución trascendental. Para una conciencia constituyente aquello que sea el otro termina siendo la idea que tiene de sí mismo. Cf. Totalidad e Infinito, p. 32; p. 131-136.

11 Nos encontramos aquí con una idea del tiempo como tiempo encarnado, como tiempo corporal, en la medida en que la salida de sí, esto es, la trascendencia que define al cuerpo, es la propia descripción de la temporalidad. Cf. Lévinas (1993), p. 88-89. 
sentido, de su inversión, la constante impugnación al privilegio otorgado a la conciencia (cf. LÉVINAS, 2012, p. 140).

\section{La carne y el rostro}

Con la noción de "carne" (chair) Merleau-Ponty se propone mostrar el sentido esencialmente reversible de nuestro ser encarnado en el mundo, en el modo de un entrelazamiento recíproco que no convierte al cuerpo en el fundamento último (Grund) del sentido, que no hace de la trascendencia del mundo, del otro, un resultado de la vida inmanente del sujeto. Con la noción de rostro (visage) Lévinas busca también dejar en claro la alteridad radical que define al Otro como lo completamente Otro, como lo absoluto separado de nosotros. Veremos que, así como la noción de carne no conlleva la negación del cuerpo, sino su exaltación, la noción de rostro no incurre en una idea abstracta del Otro, en una formalización de su ser material, fáctico, en la que sea posible hablar de un rostro sin cuerpo.

Merleau-Ponty concibe la carne (chair) como Visibilidad (Sichtigkeit) (cf. 1964b, p. 173; 1970, p. 164), como aquello en virtud de lo cual "hay" (il y a/es gibt) algo y no nada. Es la manifestación del sentido, pero como sentido sensible, encarnado. El lugar de la encarnación del sentido de lo que vemos, de lo que percibimos, no está ni en nuestro cuerpo ni en el mundo, sino justamente en el cruce, en el lugar de encuentro formado entre quien ve y lo visto, entre quien toca y lo tocado, entre el hablante y el oyente. "Hemos de rechazar, [escribe MerleauPonty], los prejuicios seculares que sitúan el cuerpo en el mundo y al vidente en el cuerpo o, inversamente, sitúan el mundo y el cuerpo en el vidente, como dentro de una caja" (MERLEAU-PONTY, 1970, p. 172). El cuerpo, decíamos, es del mundo y lo es de un modo particular. Él no es ni su amo ni su esclavo. Se encuentra en una relación solidaria, recíproca con él. Las cosas, los otros, nunca son plenamente objetos porque nos encontramos insertados, integrados a ellos por nuestro cuerpo. Así, cuando vemos a otro, aquello que permite que efectivamente sea otro a quien yo veo y que, a su vez, yo sea otro a quien él ve - y no que cada uno sea para el otro un objeto, un maniquí-, es ese vínculo sensible 
que nos ata y nos sostiene en el mundo desde nuestro nacimiento y que Merleau-Ponty llama carne (chair). Carne, porque literalmente es el tejido, el entramado sensible del que está hecho el mundo como mundo vivo, mundo de relaciones y de posibilidades. "Hay" (il y a/es gibt) visibilidad, esto es, "hay" mundo, "hay" algo para ver, para tocar, en el modo de un "lugar de cruce" (tejido), de "entrelazamiento" (entrelacs/ Verflectung) formado entre nuestro cuerpo y las cosas, entre nuestro cuerpo y el otro. Por ello, subraya el autor, la carne no es materia (cf. MERLEAU-PONTY, 1964b, p. 183), en el sentido de un hecho acabado, sino que nombra el poder de lo sensible que hace posible la comunicación: "Porque este espesor de carne constituye la visibilidad de la cosa y la corporeidad del vidente; no es un obstáculo entre ambos, sino su medio de comunicación" (MERLEAU-PONTY, 1970, p. 168).

Es en virtud del tejido de lo sensible formado entre nosotros y el mundo, que Merleau-Ponty llama carne, como debe ser entendido nuestro poder de sentir, esto es, no como el poder primordial de una única conciencia, sino "como el volverse lo sensible hacia sí mismo, como adherencia carnal de lo sintiente a lo sentido y de lo sentido al sintiente" (MERLEAU-PONTY, 1970, p. 177). Sólo así se puede comprender que en el apretón de manos ${ }^{12}$, en el abrazo, en la mirada que dirigimos al otro, este sea percibido como verdaderamente otro. La mirada que dirigimos a otro - gracias a esta comunicación instaurada en la vida sensible como entrelazamiento recíproco entre el vidente y lo visible, entre quien ve y es visto-, no convierte al otro en "alguien visto", en un ser sin mirada, ya que mirar significa a su vez ser visto, tener el poder de asumir la mirada del otro, de responder, como en Lévinas, a ella ${ }^{13}$.

12 Hans-Dieter Gondek en su artículo "Die Händedruck zwischen Merleau-Ponty und Lévinas" refiere el ejemplo, tomado por MerleauPonty de Husserl, de la "mano que toca la otra mano", para argumentar que, así como permanece una diferencia irreductible entre la mano tocante y la mano tocada, también al tocar la mano del otro, al estrechar su mano en el saludo o la despedida, él hace presencia como verdaderamente otro. Sí el otro, a quien estrechamos la mano, no es un análogo o una proyección nuestra, si su ser otro, en otras palabras, es irreductible a cualquier comparación, lo es en virtud de la vida del cuerpo, de su ser carnal, como entrelazamiento permanente entre quien ve y es visto, quien toca y es tocado (Cf. FISCHER, et al., 2001, p. 77-79).

13 Para Lévinas, sin embargo, la filosofía del cuerpo de Merleau-Ponty termina eliminando la distancia, la separación infranqueable existente entre el otro y nosotros. Si bien Merleau-Ponty rompe, observa Lévinas, con el modelo de la estructura intencional de la conciencia, en donde el otro es percibido como correlato de la noesis, como un Alter ego, termina planteando, bajo la idea de la reversibilidad sensible, la existencia de un único cuerpo, de una única vida "entre dos", que anticipa y funda la vida del otro (cf. 
Al inicio de la tercera parte de Totalidad e Infinito, titulada "El rostro y la exterioridad", Lévinas plantea justamente la pregunta de si es posible ver el rostro del otro y en qué medida su idea de la alteridad del otro, basada en la epifanía del rostro, se encuentra "más allá" de la experiencia sensible. El ser trascendente del otro presente en su rostro rompe con la sensibilidad ${ }^{14}$ porque es absoluto, porque, en términos fenomenológicos, su aparición no es relativa a otro, en el sentido de que este sea su condición de posibilidad. En términos de visibilidad, la luz formada entre el otro y nosotros, no hace posible la aparición del otro y de nosotros mismos, a modo de un destello, como si ver al otro fuese posible por un fondo de luz que abarcara también la oscuridad. En últimas, se trata de la crítica a la metáfora de la luz y de la visibilidad planteada ya en El tiempo y el Otro ${ }^{15}$ : "La visión presta una significación a la relación que ella hace posible" (LÉVINAS, 2012, p. 212). La presencia del Otro en su rostro, por el contrario, es radical porque parte de sí misma, porque viene absolutamente de sí misma (LÉVINAS, 2012, p. 213). El rostro es expresión por la palabra y quien significa, quien habla, se presenta por sí mismo. La esencia original de la expresión radica justo en que quien se expresa "se presenta él mismo, a sí mismo" (LÉVINAS, 2012, p. 222) y no en que trasmite una información o, incluso, no porque exprese un "interior", ya sea este un pensamiento o un sentimiento.

Precisemos ahora la relación que se establece entre el rostro y la palabra y de qué modo la expresión llevada a cabo por ésta rompe con la sensibilidad, con la vida corporal. ¿Qué significa esta ruptura? ¿No

LÉVINAS, 1986, p.52). Este único cuerpo formado entre el otro y nosotros es, según Lévinas, la mirada de un tercero que, ubicado desde el exterior, tiene el poder de abarcar al Otro y a nosotros mismos, eliminando las distancias (LÉVINAS, 2012, p. 30). Dicho en otras palabras, la visibilidad formada entre la mirada del otro y la nuestra - su ser visible para nosotros y viceversa- disuelve a éstas en una única visión, en una única experiencia de ver, e instaura una vida anónima, en la que ya no cuenta la vida del otro ni la nuestra. La alteridad del otro debe ser radical, irreductible y esto significa, en el contexto de su crítica a MerleauPonty, plantear la diferencia con el otro como una diferencia ética (LÉVINAS, 1986, p. 53). El rostro (visage) del Otro muestra la separación radical entre él y nosotros como diferencia ética: En el rostro el 0 tro es correspondido en su diferencia indisoluble, la cual radica en la responsabilidad para con él (LÉVINAS, 1986, p. 53).

14 "La relación con el otro es lo único que introduce una dimensión de trascendencia y nos lleva hacia una relación totalmente diferente de la experiencia, en el sentido sensible del término (relativa y egoísta)" (LÉVINAS, 2012, p. 214).

15 La metáfora de la luz es la metáfora de la conciencia como transcendencia envuelta en la inmanencia: todo objeto puede ser dicho en términos de conciencia, es decir, "puesto a la luz" (cf. LÉVINAS, 1993, p. 103).

Rev. Filos., Aurora, Curitiba, v. 30, n. 50, p. 379-396, maio/ago. 2018 
supone ya ésta, de manera original, una relación entre la mirada y el lenguaje, entre el cuerpo y la palabra? o ¿resulta irrelevante para esta ruptura que quien habla posea un cuerpo o, más exactamente, sea un cuerpo? En este caso, ¿Es el rostro, como expresión de alteridad absoluta del otro, un rostro sin cuerpo, sin mirada?

\section{El otro y la palabra}

Para Lévinas la expresión llevada a cabo por la palabra es paradójica. Se trata, como en Merleau-Ponty ${ }^{16}$, de la existencia de una palabra, de una significación, antes del lenguaje $\mathrm{e}^{17}$, de una palabra original ${ }^{18}$. Una palabra que logra romper, salir del encerramiento de lo dicho, de las significaciones establecidas; un rompimiento que tiene lugar entre el decir (dire) y lo dicho (dit). Aquello que impide comprender ese otro, observa Lévinas en su texto De otro modo que ser o más allá de la esencia, mencionado en el enunciado "De otro modo que ser", es justamente la soberanía ejercida de lo dicho sobre el decir, del significado sobre el significante, en últimas, de la lingüística y de la ontología sobre el decir (cf. LÉVINAS, 2011, p. 48). La palabra del otro y la nuestra, como palabra original, pueden romper con lo dicho, con el orden de las significaciones fijas, porque ella es expresión de sí misma, porque quiebra al yo como garante último del sentido al hacer de su significación, de su expresión, su propia subjetividad, su ser sí mismo. De este modo, rompe con la sensibilidad de la vida egoísta, interesada del yo, al mismo tiempo que la abre, la desgarra como sensibilidad de

16 Pero se debe advertir que Lévinas critica abiertamente los estudios del lenguaje que ven en el silencio la esencia de este. El silencio es, en últimas, un silencio de la razón, un intervalo que no tiene un sentido en sí mismo, sino que termina absorbido por lo dicho (Cf. LÉVINAS, 2015, p. 56 y p. 61).

17 "[U]n decir que es anterior al lenguaje, pero sin el cual no sería posible ningún lenguaje en tanto que transmisión de mensajes" (LÉVINAS, 2011, p. 61).

18 La palabra "original" no refiere la idea de origen, en un sentido primitivo o mítico, es decir, como la primera palabra pronunciada que contiene el destino de toda palabra posible. Una idea que recuerda de idéntica manera la concepción de lo originario en Merleau-Ponty. Lévinas utiliza en varios pasajes como sinónimos las palabras "original" "y "pre-original" (cf. LÉVINAS, 2011, p. 48 y p. 99, pie de página) para reiterar que su idea de lo original debe ser entendida como lo "pre-original". 
"un uno-para-el-otro" (cf. LÉVINAS, 2011, p. 58 y ss) ${ }^{19}$. La responsabilidad para con el otro, nacida como respuesta ineludible a su palabra, consiste en esta resistencia del decir a ser absorbido por lo dicho. Tal resistencia se revela en el rostro del otro, y para el otro en nuestro rostro, pero no como un absoluto completamente invisible, sino como un absoluto que ha dejado su huella. La huella se inscribe, se marca en el rostro del otro como el modo de su misma manifestación y no como un rasgo entre otros. Ella luce, afirma Lévinas, como el rostro del otro (cf. LÉVINAS, 2011, p. 56), al margen de su ser absoluto. Un margen de visibilidad de un Otro que también es sujeto, que, al igual que nosotros, es un alguien concreto "ante quien (o a quien, sin paternalismo de ningún tipo) y aquel de quien respondo" (LÉVINAS, 2011, p. 56). Se trata de una subjetividad, la instaurada por la palabra, "obligada a la vista del otro" (LÉVINAS, 2011, p. 56), que resiste en su sensibilidad, pero no como un simple residuo, sino precisamente como el lugar de la ruptura de lo dicho.

¿Cómo entender este prodigio de la palabra, de decir, de significar en el modo de un decir "[...] que se descubre - esto es, que se desnuda de su piel - como sensibilidad a flor de piel, a flor de nervios, que se ofrece hasta el sufrimiento?" (LÉVINAS, 2011, p. 60). Si no se trata aquí únicamente del uso de una metáfora ¿en qué sentido la palabra es ella misma sensibilidad? La palabra rompe la piel, nuestra sensibilidad, pero no, en sentido estricto, para despojarse completamente de ella, sino para afirmarse en la herida, en su dolor. El dolor, afirma Lévinas, es el "reverso de la piel" (2011, p. 103), en el que sufrimos "por una astilla que quema la carne" (2011, p. 103). El paso, la mutación del yo al sí mismo, en el que se instaura la vida de un "uno-para-el-otro", lo que Lévinas llama la substitución, tiene lugar en la vida del cuerpo: "El retorno del Yo en Sí mismo, la des-posición, o la destitución del Yo es la modalidad propia del des-interés a modo de vida corporal volcada a la expresión y al dar [...]" (LÉVINAS, 2011, p. 104). El dolor padecido en la substitución, en-ser-para-el-otro a pesar de nosotros mismos, no es un dolor de un espíritu sin cuerpo, sino un dolor físico, un dolor de

19 Si se comprende la ruptura realizada aquí por la palabra se comprenderá a su vez por qué este otro es verdaderamente otro, por qué no se encuentra absorbido por el ser, en el sentido de "otra manera de ser".

Rev. Filos., Aurora, Curitiba, v. 30, n. 50, p. 379-396, maio/ago. 2018 
alguien que tiene un nombre, o mejor aún, que es nombre, un individuo (cf. LÉVINAS, 2011, p. 110).

Merleau-Ponty sostiene que, respecto a la relación cuerpo y lenguaje, es en la expresión por la palabra que el otro, de manera muy cercana a lo planteado por Lévinas, llega a ser otro "en un sentido mucho más radical" (MERLEAU-PONTY, 1971, p. 202). La palabra (parole) es lo que tenemos de más propio, lo más individual, porque es creación (Schöpfung) de nosotros mismos (MERLEAU-PONTY, 1971, p. 204). A diferencia de la lengua (langue), la palabra (parole) es el lenguaje que nos hemos apropiado, la palabra hablante (parole parlant), la palabra que tenemos para expresarnos. Palabra instituyente, operante, inacabada, antes que palabra instituida, integrada a un sistema acabo de signos. La palabra del otro, y también nuestra palabra, como palabra viva, actuante, tiene como rasgo fundamental romper con el lenguaje establecido, con el orden de las significaciones acostumbradas, si verdaderamente es palabra del otro. El poder de la palabra radica, entonces, en que forjamos con ella, en una experiencia de apropiación permanente, nuestra propia manera de significar, de relacionarnos con los demás y con el mundo. Ella exige de nosotros nuestra propia transformación, crear nuevas maneras de significar y, en este sentido, muestra, así como el cuerpo, nuestra vulnerabilidad. Por la palabra no solamente somos otro para el otro, sino que llegamos a ser otro para nosotros mismos.

Ahora bien. Este poder creador, inaugurador del lenguaje, es también para Merleau-Ponty paradójico: refiere el ser mismo del lenguaje, su autonomía, pero como lenguaje encarnado. El poder del lenguaje radica en ser expresión, no de una realidad interior, a modo de un pensamiento, un sentimiento, sino expresión de sí mismo. Expresar "algo" no cosiste en encontrar las palabras adecuadas para nombrar la idea, el pensamiento que queremos transmitir, como quien busca, afirma MerleauPonty, un martillo para clavar un clavo. La expresión es expresión de sí misma, porque ella tiene el poder de crear su propia significación ${ }^{20}$.

20 Los escritores, observa Merleau-Ponty, saben muy bien en que consiste este poder creador del lenguaje: "Qué es lo que sabe el escritor? Lo único que sabe es que el que habla o escribe comienza por estar mudo, apuntando hacia lo que quiere significar, hacia lo que va a decir" (MERLEAU-PONTY, 1971, p. 29). Lo que quiere escribir, a lo que "apunta" el escritor cuando escribe, pero también toda persona cuando habla, es este silencio, este vacío de sentido que penetra, que atraviesa las palabras mismas. Las 
Lo que decimos, lo expresado, se forma en el momento de la expresión. Se debe tomar, por ello, el sentido literal de la palabra expresión, como advierte al respecto Fracois Dastur (2001), esto es, como ex-primir, sacar el jugo a algo. La significación es, señala reiteradamente MerleauPonty, segregada por el signo (1971, p. 38). Lo expresado, lo dicho, en la expresión, es, por decirlo así, el "rendimiento", la "producción" misma de la expresión. La significación, en otras palabras, no está desprovista de lenguaje. Quien habla nunca tiene una idea acabada de lo que va a decir, así que expresar-se consiste en el trabajo paradójico de nombrar un sentido que se forma en el momento mismo de la expresión, que no antecede a esta como un bloque, a modo de una frase, un pensamiento ya dichos. No hay un pensamiento puro, sin lenguaje. Sobre esta concepción del lenguaje escribió Lévinas: "Merleau-Ponty, entre otros, y mejor que otros, mostró que el pensamiento desencarnado, que piensa la palabra antes de hablarla...era un mito"' (2012, p. 229).

\section{A modo de conclusión}

Ambos autores plantean una rehabilitación de lo sensible como punto de partida de su concepción del cuerpo y del lenguaje: La vida sensible del cuerpo como "lugar" del acontecimiento del sentido. Hay sentido, significación, en la vida del cuerpo. La más mínima percepción, la sensación de lo áspero, de lo liso, de lo frío, de lo caliente, pero también de tristeza o de alegría, son ya para Merleau-Ponty la expresión misma de un sentido. El gozo, el placer, pero también el dolor, el sufrimiento, la vulnerabilidad, son para Lévinas sensaciones, no se reducen a la relación sujeto-objeto, a la relación de conocimiento (cf. LÉVINAS, 2011, p. 120); en ellas la vida del cuerpo se afirma como sujeto, como sí mismo. Hay una separación más originaria que la relación sujeto-objeto y es la separación corporal (leibliche Spaltung). El cuerpo, en términos

palabras no contienen el significado como un recipiente el líquido, sino que éste emerge, es segregado entre las palabras. Es el silencio de lo "aún no dicho", de lo que "se va a decir", de lo que no está contenido en las palabras dichas; un silencio que hunde sus raíces en la experiencia sensible, en lo que ha sido vivido y que "aún" no se ha expresado en palabras. Asi, "Io" que quiere decir el escritor es el sentido mudo, silencioso que habita su experiencia y que se instala entre el decir y lo dicho. 
de Lévinas, es el régimen de la separación (LÉVINAS, 2012, p. 181), en él se da el movimiento de interiorización y exteriorización, de un sí mismo corporal que para ser necesita asumir aquello que no es, en el modo de una inversión que alcanza también la expresión por la palabra y no sólo la vida material del cuerpo en cuanto tal. Pero esta separación originaria es, paradójicamente, como en Merleau-Ponty, una división que muestra el entrelazamiento corporal existente entre nosotros y los demás. La vida del "uno-para-el-otro" vivida en el sí mismo lleva para Lévinas "toda la gravedad del cuerpo" (LÉVINAS, 2011, p. 128), en el sentido en que es nuestro propio cuerpo el que ofrecemos para la expresión y el sacrificio por el otro. El "uno-para-el-otro" no plantea la disolución del otro ni de nosotros mismos, porque precisamente su significación, esto es, su ser-para-otro, es la propia vida del cuerpo como sensibilidad, vulnerabilidad, pasividad. Dicho en forma más precisa. Su modo de significar es la sensibilidad, la vida sensible del cuerpo, su exposición al gozo y al sacrificio. En esta relación el otro permanece irreductible, absoluto, porque "lo sensible" en ella no es conceptualizado, no es comprendido; es exposición al otro, ser-para-el-otro, en una pasividad que es "la posibilidad misma de dar" (LÉVINAS, 2011, p. 126).

Pero Lévinas opone esta idea de lo sensible ${ }^{21}$ a la expuesta por Merleau-Ponty, al considerar que, como en Husserl, Merleau-Ponty convierte la sensación en un momento del conocimiento bajo la idea de una visibilidad total. Lo mismo podría argumentarse contra Lévinas, sin razón a nuestro parecer, si se afirmara que el ser absoluto del otro, su infinitud irreductible expuesta en su vulnerabilidad, en su rostro que nos mira, termina siendo soportado en el principio formal "no matarás". No hay en Merleau-Ponty la idea de una visibilidad total, en el sentido de una luz del ser que irradie a los entes, como tampoco en Lévinas un sentir universal, un padecimiento del mundo, anterior al sentir de los hombres, de los entes. Para Merleau-Ponty el poder del cuerpo de comprender, de interpretar no es, en modo alguno, del orden del conocimiento. Lo originario, entendido como el sentido de

21 El ser de lo sensible para Lévinas radica en una sensación más originaria, cuya significación "pre-original" contiene "los motivos del origen y del aparecer" (LÉVINAS, 2011, p. 122). 
lo sensible, explota (MERLEAU-PONTY, 1964b) y la labor de la filosofía no consiste en recomponer su unidad, como si fuese la unidad de un tiempo, de una palabra primitiva, legendaria. La unidad formada en la reversibilidad no se anticipa al sentido en términos de conocimiento. Este rompimiento, esta explosión de la vida sensible, no es un paliativo o un simulacro, sino un rompimiento capaz de transformar nuestra manera de percibir, de pensar; una ruptura que, en el orden del lenguaje, instaura el nacimiento de la palabra del otro y de nuestra palabra. La "comprensión" de la desnudez del rostro del otro, de su alteridad absoluta, no anticipa la expresión de su palabra. Es porque el otro nos habla, porque nos dirige la palabra que, como también en Merleau-Ponty, descubrimos nuestro ser-para-otro, en el modo paradójico de una comprensión de lo incomprensible, de una expresión de lo inexpresable (LÉVINAS, 2015, p. 70). No por ello debemos concluir que, como lo hace Lévinas con Merleau-Ponty, nos hallamos en un círculo cerrado, en el que la significación se anticipa a la expresión. La expresión es para Merleau-Ponty, como para Lévinas, expresión de sí misma, lo que quiere decir que "aquello" expresado en la palabra del otro, su significación, no es, por decirlo así, ontológicamente distinto a él mismo, no es un sustituto, en el modo de una representación suya. Lo que expresa la palabra del otro es precisamente su misterio, su ser absoluto, irreductible. Es el misterio del otro, y no otra libertad, advierte Lévinas, lo que se da en la relación con el otro (cf. LÉVINAS, 2015, p. 63); el misterio, en términos de Merleau-Ponty, de una "visibilidad de lo invisible", de la existencia de otro sujeto corporal ilocalizable, que no podemos señalar con el dedo, inobjetivable.

\section{Referencias}

DASTUR, F. Chair et langage. Essais sur Merleau-Ponty. La Versanne: Encre Marine, 2001. 
GONDEK, H-D. Der Händedruck zwischen Merleau-Ponty und Lévinas. En: Vernunft im Zeichen des Fremden. Zur Philosophie von Bernhard Waldenfels. (Fischer, M. et al., Editores). Frankfurt am Main: Suhrkamp, 2001.

GUTIÉRREZ, J. El despliegue de la carne, la palabra y el rostro: De Merleau-Ponty a Lévinas. Cuadernos de Filosofía Latinoamericana, v. 31, n. 103, p. 145-152, 2010.

LÉVINAS, E. Über die Intersubjektivität. Anmerkungen zu Merleau-Ponty. En: Leibhaftige Vernünf. München: Wilhelm Fink Verlag, 1986.

LÉVINAS, E. Escritos inéditos 2. Palabra y silencio y otros escritos. Trad. Miguel García Baró y Mercedes Huarte. Madrid: Editorial Trotta, 1987.

LÉVINAS, E. El tiempo y el otro. Trad. José Luis Pardo. Barcelona: Paidós, 1993. LÉVINAS, E. Théorie de l'intuition dans la phénoménologie de Husserl. Paris: Vrin, 2001. LÉVINAS, E. La teoría fenomenológica de la intuición. Salamanca: Ediciones Sígueme, 2004.

LÉVINAS, E. De otro modo que ser o más allá de la esencia. Trad. Antonio Pintor Ramos. Salamanca: Ediciones Sígueme, 2011.

LÉVINAS, E. Totalidad e infinito. Trad. Miguel Garcia-Bar. Salamanca: Ediciones Sígueme, 2012.

MERLEAU-PONTY, M. Phénoménologie de la perception. Paris: Gallimard, 1945. MERLEAU-PONTY, M. Signos. Trad. C. Martínez y G. Oliver. Barcelona: Editorial Seix Barral, 1964a.

MERLEAU-PONTY, M. Le visible et l'invisible. Paris: Gallimard, 1964b.

MERLEAU-PONTY, M. Lo visible y lo invisible. Trad. J. Escudé. Barcelona: Editorial Seix Barral, 1970.

MERLEAU-PONTY, M. La prosa del mundo. Trad. Francisco Pérez. Madrid: Tauros, 1971.

MERLEAU-PONTY, M. Fenomenología de la percepción. Trad. J. Cabanes. Barcelona: Editorial Planeta-De Agustini, 1984. 
SALAS, R. Intersubjetividad, otredad y reconocimiento en el pensar de Emmanuel Levinas y Maurice Merleau-Ponty. Diálogos fenomenológicos acerca del Otro. Revista de Filosofía, n. 67, p. 7-41, 2011.

WALDENFELS, M. Phänomenologie in Frankreich. Frankfurt am Main: Suhrkamp, 1983.

WALDENFELS, M. Exploraciones fenomenológicas acerca de lo extraño. Gustavo Leyva (Editor). Barcelona/México: Siglo XXI Editores/Anthropos, 2015.

Recibido: 28/10/2017

Received: 10/28/2017

Aprobado: 21/06/2018

Approved: 06/21/2018 